\title{
Tensile properties of impregnated sugar palm (Arenga pinnata) fibre composite filled thermosetting polymer composites
}

\begin{abstract}
The effect of fibre modification via vacuum resin impregnation on tensile properties of sugar palm fibre reinforced thermosetting composites was studied. The fibres were impregnated with unsaturated polyester, vinylester and epoxy at the pressure of $600 \mathrm{mmHg}(79.99 \mathrm{kPa})$ for 30 mins. After curing time, it was observed that tensile strength of impregnated fibre was significantly increased with epoxy (EPX) was the best with $188.06 \mathrm{MPa}$. It was followed by unsaturated polyester (UP) and vinylester (VE) with 107.12 MPa and 158.31 MPa. However, tensile modulus for sugar palm fibre impregnated with EPX increased up to $21 \%$ compared to un-impregnated sugar palm fibre followed by UP (12.7\%) and VE (8.4\%). It was observed that different impregnation agents gave different values of strength of sugar palm fibre composites.
\end{abstract}

Keyword: Vacuum resin impregnation; Sugar palm fibre; Tensile properties; Unsaturated polyester; Vinylester; Epoxy 